\title{
Intercultural Development: Study Abroad Vs. On-Campus Study
}

\author{
Philip H. Anderson \\ University of St Thomas
}

\section{Leigh Lawton}

University of St Thomas

\section{Introduction}

The number of study abroad programs offered by colleges and universities has grown consistently over the past decade and future growth is forecast at eight percent annually (Institute for International Education, 2006). In addition to their educational goals, these programs serve as a recruitment tool for prospective students. Increasingly, students base their college selection on study abroad opportunities as well as academic offerings and campus life considerations (Internationalization of U.S. Higher Education, American Council on Education Report 2000). As international travel has become more commonplace and as the economies of the world have become more interdependent, both students and faculties are recognizing the importance of increasing students' ability to function effectively in a global community. Study abroad programs are seen by many as an effective means to provide students with the competencies required by this changing environment.

Unfortunately, study abroad is an expensive, resource-intensive activity both for students and for their home institutions. As study abroad programs divert resources that could otherwise be allocated to on-campus programs, some question whether the study abroad experience achieves its desired objectives. Gillespe (2002) has called for improved assessment of study abroad programs. She argues for establishing minimum standards for every program that include both qualitative and quantitative measures. With an estimated 200,000 American students studying abroad in 2006, and with this number growing annually, program administrators and international scholars are increasingly being asked to document the learning outcomes associated with study aboard (Vande Berg, 2001). Accrediting bodies such as North Central (Higher Learning Commission, 2007) and the Association to Advance Collegiate Schools of Business (2007) are also calling upon colleges and universities to 
formally assess the extent to which they are preparing their students to live and work in an increasingly interdependent global environment.

While the specific objectives established for study abroad programs vary from institution to institution, academic and intercultural competencies are common to virtually all programs (Greenholtz, 2000; Hammer, Bennett and Wiseman, 2003). Academic competence focuses on the specific discipline studied, while intercultural competence relates to the broad goal of enhancing student appreciation of differences among cultures coupled with the ability to function effectively in a foreign environment. The assessment of academic competence achieved as part of a study abroad program is routinely accomplished with the submission of course grades. There is, however, no similar mechanism for assessing whether desired intercultural competencies are achieved.

Broadly conceived, intercultural competence helps people live and work with people of diverse cultural backgrounds (Landis and Bhagat, 1996). This in turn contributes to building the essential leadership skills necessary for operating effectively in an increasingly complex global environment (Earnest, 2003). Further, tensions created as a consequence of the global war on terror have drawn attention to the strategic value and overall importance of developing essential cross-cultural skills (Lincoln Commission, 2005).

\section{Literature Review}

While study abroad programs provide an opportunity for achieving sensitivity to cultures, Kelly (1963) argues that simple exposure to a culture is not sufficient to guarantee improved cultural sensitivity. He contends that a person can witness an event without ever experiencing it (p. 73). It is Kelly's opinion that the impact of an experience is a function of one's ability to categorize events. In short, a student could participate in a study abroad program without experiencing the culture in which he or she resided.

Although there have been increasing pressures to document the impact of study abroad programs, only a limited number of studies have employed pre-post measures in an attempt to measure the changes produced by the experience. Medina-López-Portillo (2004), Engle and Engle (2004), and Paige, Cohen, and Shively (2004) have examined cross-cultural sensitivity in study abroad programs designed to improve language skills. Paige et al. (2004) found that U.S. students studying language in French and Spanish speaking countries improved overall cross-cultural sensitivity and Engle and Engle (2004) reported similar findings. Engle and Engle also observed that students involved in longer-term programs (full year versus one semester) showed a greater gain in cross-cultural sensitivity. By contrast Medina-López-Portillo 
(2004) found little evidence for improvement as the result of a seven-week or semester-long program of study in Mexico.

Short-term programs (one month or less) have also been shown to have an impact on cross-cultural development. For example Anderson, Lawton, Rexeisen and Hubbard (2006) report a positive impact on intercultural sensitivity for a short-term (four week) non-language-based study abroad program. Patterson (2006) compared the effects of a short-term (two to four week) study abroad experience with that of on-campus cross-cultural study. Patterson found that there was a small improvement in intercultural sensitivity for those that studied abroad and no improvement for those with the traditional classroom experience.

More recently, a consortium centered at Georgetown University's Office of International Programs reported on an extensive, multi-year study of student learning regarding language skills and intercultural development resulting from study abroad programs (Vande Berg, Connor-Linton, Paige, 2009). Their findings showed support for gains in intercultural competence. Their results were moderated by variables such as the length of the study abroad experience, the extent to which the students were immersed in the local culture while abroad, and the presence of a "cultural mentor" abroad. However, they also reported that "a sizable number of students abroad did not learn significantly more than control students.” (p. 25).

\section{Measuring Cross-Cultural Development}

One of the major obstacles to documenting the impact of a study abroad program is defining precisely what should be measured. In our experience, it is not uncommon for students returning from an overseas experience to report that it was a profound, even life-changing event. However, it seems to be difficult for students to articulate the ways in which they have changed. Anecdotally, it seems that part of the development students perceive involves enhanced cultural sensitivity and cultural competence. However, constructs like cultural sensitivity and cultural competence are abstract, nebulous concepts. Due to the inherent ambiguity of these constructs, it is not surprising that many approaches to measuring cross-cultural competence have been proposed over the years. Examples of instruments used include the following. The Intercultural Adjustment Potential Scale (ICAPS) is used to help identify elements of a study abroad experience that contribute to intercultural adjustment (Savicki et al., 2004). The International Education Survey (IES) assesses how an international experience impacts personal and intellectual development (DeDee and Stewart, 2003). The Global Awareness Profile (GAP) is used to measure the degree to which a person can recognize and appreciate the size, 
complexity and diversity of cross-cultural experiences so that he or she can form an integrated worldview (Corbitt, 1998). The Beliefs, Events and Values inventory (BEVI) is based on the level of agreement with various belief-value statements and assesses a number of characteristics related to cross-cultural competency, e.g., openness, tendency to stereotype, receptivity, etc. (Shealy, 2004). The BEVI instrument is currently undergoing further validation study through a project sponsored by the Forum on Education Abroad. Yet another approach is the Intercultural Development Inventory (IDI) by Hammer and Bennett (2002). Their instrument measures the respondent's overall level of intercultural sensitivity based on an individual's progression through six stages of cultural development. Recently, Braskamp, Braskamp, Merrill, and Engberg (2010) developed the Global Perspective Inventory (GPI). The GPI is based on a global, holistic developmental view that integrates cognitive, intrapersonal, interpersonal dimensions, and includes scales to measure each of the three dimensions plus a cluster named "global citizenship" which combines items from the other scales.

\section{The Study}

This study, conducted during Fall Semester 2009, employed a prepost assessment of students in a junior-level, semester-length study abroad program for students majoring in business, plus a parallel pre-post assessment of students enrolled in two on-campus courses. The campus courses were both primarily junior-level, one a required business course and the other, a liberal arts course. These two courses provided comparison groups to help reveal changes in intercultural development due simply to the passage of time. The liberal arts course was measured to assess differences that might exist due to the students' major field of study.

\section{The Assessment Instruments}

As noted above, there are many competing instruments for measuring intercultural development. Considerable variability exists across instruments in the format of the instrument, in the specific constructs each measures, and in the nature of the questions asked. Because there is no consensus as to which instrument is most valid for assessing development, we chose to use two different instruments: the Intercultural Development Inventory (IDI) by Hammer and Bennett (2002) and the Global Perspective Inventory (GPI) by Braskamp et al (2010). Although IDI and GPI both are designed to measure intercultural competence, the theoretical foundation of the two instruments and the scales for each appear to be quite different. (A description of the scales used in the instruments is provided below.) We wished to examine the 
relationship between the two instruments and the extent to which the results obtained from them would coincide. In addition, we wished to learn if using two different instruments would provide a broader assessment of the impact of a study abroad program on it participants.

\section{The Intercultural Development Inventory (IDI) V2.3}

Hammer and Bennett's (2002) IDI measures an individual's overall stage of development in addition to providing various scales that approximate Bennett's stages of cross-cultural development. The first stages of development (Denial/Defense, Reversal, and Minimization) represent an ethnocentric perspective whereas the latter stages (Acceptance/Adaptation and Encapsulated Marginality) represent the degree to which a person has developed an ethnorelative perspective (See Exhibit 1). For example, the underlying construct that Hammer and Bennett label as "defense against differences" is properly understood to be a more-or-less rigid judgment that one culture is superior to another. We provide a description of the IDI scales from Hammer and Bennett (2002) in Exhibit 2.

We chose to use Hammer \& Bennett's Intercultural Development Inventory (2002) for three reasons. First, the IDI was designed specifically to measure cross-cultural development, which is the focus of this study. Second, the IDI has been subjected to extensive psychometric testing (Hammer, Bennett, and Wiseman, 2003; Paige et al., 2003). Third, it is an established, widely-used instrument for assessing intercultural development.

\section{The Global Perspective Inventory (GPI)}

We chose to use the Global Perspective Inventory (GPI) developed by Braskamp, et al. (2008) because it aims to measure an individual's growth and development as a consequence of life experiences. [Note: The GPI has since been revised (Braskamp, Braskamp, Merrill, and Engberg, 2010).] The GPI has been used extensively with college students. It is constructed to measure how people gain insight into the world around them, and how these insights influence their self-perception and interpersonal relationships. As a consequence, the GPI's questions are designed to reflect the integration of its scales with daily life. Since our study was designed to compare students studying abroad with those studying on campus, we felt the IDI and GPI would provide interesting alternatives for assessing the intercultural development of the subjects over the duration of the study.

The GPI has nine scales described in Exhibit 3. Given the purpose of this study and the description of the Community and Well-being scales, we did not use these two scales in our analysis of the data.

Braskamp, Braskamp, Merrill, and Engberg (2010) have reported on the 
GPI's validity and reliability, which range from 0.65 and 0.76 . For our subjects, we found a Cronbach alpha of only 0.44 for the Cognitive Knowing scale. Consequently, we did not use this scale in our analysis. [Note: The newest version of the Knowing scale has been revised. Braskamp, Braskamp, Merrill, and Engberg (2010, p. 11) report the latest scale's reliability is .6] Cronbach alphas for the other scales ranged from 0.59 to 0.82 . While Cronbach alphas were not as strong as we would have preferred for two of the scales (Affect, 0.59 and Social Interactions, 0.59 ), we chose to include them in our analysis. Therefore, the tests of the study's hypotheses were based on the six GPI scales of Cognitive Knowledge, Intrapersonal Identity, Intrapersonal Affect, Interpersonal Social Interactions, Interpersonal Social Responsibility, Global Citizenship.

\section{The Hypotheses}

We tested the following six hypotheses:

Students who participate in a semester long, faculty-led study abroad program will have:

H1: pre-test cross-cultural sensitivity scores, as measured by the IDI, that do not differ significantly from those of on-campus students who are at a similar stage in their academic career.

$\mathrm{H} 2$ : pre-test cross-cultural sensitivity scores, as measured by the GPI, that do not differ significantly from those of on-campus students who are at a similar stage in their academic career.

$\mathrm{H} 3$ : a significant increase in cross-cultural sensitivity at the conclusion of the semester (pre-test to post-test) as measured by the IDI.

H4: a significant increase in cross-cultural sensitivity at the conclusion of the semester (pre-test to post-test) as measured by the GPI.

$\mathrm{H} 5$ : a greater change in pre-test to post-test cross-cultural sensitivity scores, as measured by the IDI, than those of comparable students who studied on-campus.

H6: a greater change in pre-test to post-test cross-cultural sensitivity scores, as measured by the GPI, than those of comparable students who studied on-campus.

\section{Methodology}

\section{Subjects}

The subjects in this research were traditional students at a medium-sized, 
private Midwestern university in the United States. The undergraduate student body consists of less than $10 \%$ international students or students of color.

Three subject groups were sampled from this population: students participating in a semester-length study abroad program (SAB); students enrolled in a business course on organizational behavior (Mgmt); and students enrolled in a liberal arts course on communication theories and methods (Comm). The sample size for each of these three groups was 39, 41 and 39 respectively.

Data were collected for the three groups for the following demographic variables: age, gender, ethnic identity, year in school (i.e., Sophomore, Junior, Senior), previous participation in a study abroad program, level of participation in activities relating to their own culture or other cultures, and whether they were international students studying in the U.S. There were significant differences among the three subject groups for age, gender, and year in school. Average age for SAB, Mgmt, and Comm were 20.5, 20.8 and 19.9 years, respectively. Although the difference in ages was small, the Comm students were significantly younger than the other two groups. The percentage of students who were women was $53.8 \%, 39.0 \%$, and $59.0 \%$ for those three groups, respectively. There were also significant differences in the percentage of students who were Juniors in the three study groups $(\mathrm{SAB}=97 \%, \mathrm{Mgmt}=$ $54 \%$, Comm $=31 \%$ ). We found no significant differences for any of the other demographic variables.

For those subjects participating in the study abroad program (described below), Hammer and Bennett's (2002) Intercultural Development Inventory (IDI) and an earlier version of Braskamp, et al.'s (2010) Global Perspective Inventory (GPI) were first administered at the beginning of the semester prior to departure from the U.S. The second administration of the IDI occurred at the end of the term but prior to returning home. Collection of the data and analysis of results were conducted under supervision of faculty trained and certified by the Intercultural Communication Institute.

For the subjects in the two on campus courses, the two instruments were administered during the first week and the last week of the semester. This was the same semester in which the study abroad subjects were measured.

\section{The Study Abroad Program}

The program was led by a faculty member from the home institution. The students took two business courses and two liberal arts courses. Classroom instruction was conducted by the U.S. faculty member, who taught one of the business courses, and by British instructors, who taught the remaining three courses. Classes met during the day, leaving evenings for the students 
to explore the local surroundings. In addition to classroom duties, the U.S. faculty member served as an academic advisor, counselor, and overseer of a service learning project in which the students participated as part of the study abroad program. For the service learning project, the students worked with a number of non-profit organizations in the British community.

The students' accommodations were with British families. Student involvement with the families varied considerably but often included shared meals and conversations regarding British life. The program also included day trips to sites such as Oxford and Bath. In addition, the students traveled on weekends to various European locations providing additional opportunity to observe and experience cross-cultural differences.

\section{Results}

\section{Moderating Variables}

The three subject groups were tested for moderating effects caused by the following variables: age, gender, ethnic identity, year in school (i.e., Sophomore, Junior, Senior), previous participation in a study abroad program, level of participation in activities relating to their own culture or other cultures, and whether they were international students studying in the U.S. We found no moderating effects from these variables on the results.

Hypothesis 1 Students who participate in a semester long, faculty-led study abroad program will have pre-test cross-cultural sensitivity scores, as measured by the IDI, that do not differ significantly from those of on-campus students at similar stage of their academic career.

Hypothesis 2 -Students who participate in a semester long, faculty-led study abroad program will have pre-test cross-cultural sensitivity scores, as measured by the GPI, that do not differ significantly from those of on-campus students who are at a similar stage in their academic career.

The results for the test of Hypotheses 1 and 2 are shown in Exhibits 4 and 5. No statistically significant differences were found for the pre-test scores on either the IDI or the GPI between the students who participated in the study abroad program (SAB) and the students enrolled in a liberal arts course on communication theories and methods (Comm).

However, significant differences were found for a number of IDI and GPI scales between the students who participated in the study abroad program $(\mathrm{SAB})$ and the students enrolled in the business course on organizational behavior (Mgmt). As noted above, tests conducted on a number of possible 
moderating variables revealed no significant differences. Consequently, the underlying cause for this difference is unclear. As a result, there is mixed support for Hypotheses 1 and 2. It is interesting to note the direction of the differences for the scales in question. We were surprised to find that in all but one case (the Cognitive Domain - Knowledge of the GPI), the on campus students had higher scores than those of the SAB students. We anticipated that if Hypotheses 1 and 2 were rejected, it would be because students with higher cross-cultural sensitivity were self-selecting into the study abroad program. In fact, what we found is that the study abroad students generally scored lower than their on-campus counterparts on these dimensions.

Hypothesis 3 Students who participate in a semester long, facultyled study abroad program will have a significant increase in the development of cross-cultural sensitivity at the conclusion of the semester (pre-test to post-test) as measured by the IDI.

Hypothesis 4 Students who participate in a semester long, facultyled study abroad program will have a significant increase in the development of cross-cultural sensitivity at the conclusion of the semester (pre-test to post-test) as measured by the GPI.

Exhibits 6 and 7 show the results for the test of Hypotheses 3 and 4. Significant pre-post differences for the students who participated in the study abroad program (SAB) were found both for the IDI and the GPI. Both instruments provided strong support that the study abroad experience had a significant impact on the intercultural development of the students participating in the program. Based on these results, Hypotheses 3 and 4 were supported.

Hypothesis 5 Students who participate in a semester long, faculty-led study abroad program will have a greater change in pre-test to post-test cross-cultural sensitivity scores, as measured by the IDI, than those of comparable students who studied on-campus.

Hypothesis 6 Students who participate in a semester long, faculty-led study abroad program will have a greater change in pre-test to post-test cross-cultural sensitivity scores, as measured by the GPI, than those of comparable students who studied on-campus.

The results for the test of Hypotheses 5 and 6 are shown in Exhibits 8 and 9. There was clear support that students participating in the study abroad 
program showed greater gains on intercultural development than did the liberal arts students studying on campus for both the IDI and GPI. In 23 of 26 possible relationships, the change was in the predicted direction with the $\mathrm{SAB}$ students showing greater change than did the on-campus students. Only in three cases did the on-campus students fare better than the SAB students - Defense and Denial on the IDI for the SAB versus both the Mgmt and Comm students and Interpersonal Social Responsibility on the GPI for the $\mathrm{SAB}$ versus the Comm students. For those relationships that were statistically significant, all favored the $\mathrm{SAB}$ students over on-campus students. Fifteen cases were significant beyond the 0.05 level and three more were significant beyond 0.10 .

It is worth noting that all changes in the Defense and Denial scores on the IDI were in a negative direction; this indicates that the mean scores for students in all three groups actually declined over the course of the study. While the difference in the changes for the SAB versus the Mgmt or Comm groups were not statistically significant, they were in a direction contrary to expectations (the SAB students' scores declined more than those of either oncampus group). Although these findings are mildly disappointing, they are not overly surprising. Most students scored quite high on the Defense and Denial scale on pre-test - on a five point scale, the means were 4.13, 4.13, and 4.17 for SAB, Mgmt, and Comm, respectively. Because students began the study with such high scores on this scale, there was little room for improvement. Further, a slight decline in scores on this scale is consistent with earlier research of Anderson, et al., 2006.

\section{Discussion and Conclusions}

\section{The Relationship between the IDI and GPI}

Since we have two instruments that are designed to measure related constructs, we ran correlations between the scales of these instruments to search for similarities. The results of this analysis are shown in Exhibit 10 . While several of the correlations were statistically significant, none was high enough to indicate a substantive relationship between the scales of the two instruments. The strongest correlation (0.372) was found for the scores on the post-test IDI Denial and Defense scale and the GPI Intrapersonal Affect scale; knowing the score for one of these variables enables us to explain only $14 \%$ of the variation in the other scale. Thus, for practical purposes the scores on the two instruments are quite independent. The correlation between the overall score for the IDI and the grand mean for the GPI reinforces the essential 
independence of the instruments. While the correlation between the two was significant $(\mathrm{p}=0.020)$, the correlation coefficient was only 0.23 - that is, only about $5 \%$ of the variation in the scores on one could be explained by knowing the scores on the other. The post-test correlation was only 0.041 (with a p-value of 0.684 ).

\section{Hypothesis Results}

\section{Hypotheses 1 and 2.}

We found mixed support for the hypotheses that there would be no significant differences in the intercultural development of students choosing to study abroad versus students studying on campus, prior to their study abroad experience. While we found no significant differences between the study abroad students (SAB) and the liberal arts students (Comm), we did find that students enrolled in a business course on organizational behavior (Mgmt) scored higher in their pre-test scores than the SAB students on a number of scales for both the IDI and GPI. It is not clear why this difference occurred. There were no demographic differences between these two sample groups.

\section{Hypotheses 3 and 4.}

We found strong support that students who participated in the semester long, faculty-led study abroad program (SAB) had a significant increase in the development of their cross-cultural sensitivity. We found this occurred for four of the six IDI scales and six of the seven GPI scales measured. Based on these pre-post results, we are confident that students who participate in a semester long study abroad program will become more inter-culturally sensitive as a result of their experience.

\section{Hypotheses 5 and 6.}

On almost every dimension of the IDI and the GPI, the study abroad students showed greater change in scores than did the on-campus students. Eighteen of the 26 possible relationships were significant and three more were in the predicted direction.

\section{The IDI Versus the GPI for Assessing Intercultural Development}

The personal growth that occurs as a consequence of a study abroad experience is, by definition, a uniquely individual experience. Two students participating in the same study abroad program could each undergo a transformational experience, but see little in common between them regarding that experience. How each student internalizes their intercultural experiences 
is moderated by their prior experiences, both international and domestic.

Given the personalized nature of an international experience, one motivation for conducting this study was to determine how dependent the results of an examination of the impact of a study abroad program is on the particular instrument used to assess intercultural development. For this reason, we collected pre-post data using two different instruments. While the IDI and GPI purport to measure a similar construct, the changes occurring as a result of exposure to other cultures, we found no meaningful correlations between the IDI and the GPI scales; it is apparent that the IDI and GPI measure different dimensions of intercultural development. From this analysis we conclude that the two instruments are not interchangeable; researchers could quite possibly obtain substantially different results depending upon the instrument used.

\section{Study Abroad and Intercultural Development}

Although the IDI and GPI apparently measure different dimensions of an intercultural experience, our analyses based on the two instruments yielded strikingly similar findings - in the pre-test, students participating in the SAB program did not differ from the students enrolled in an on-campus liberal arts course, but did show some differences from an on-campus management course. In the post-test, students in the SAB program showed greater gains in intercultural development than did their on-campus counterparts both on the IDI and on the GPI. The study results provide convincing support for the proposition that participation in a semester-length study abroad experience yields a significant increase in the participants' intercultural development.

The fact that similar differences were found despite the dissimilarity of the instruments provides fodder for speculation. As noted earlier, students report that studying abroad is a profound experience for them, but they find it difficult to articulate the changes they have undergone. Perhaps this is because the changes can occur in many different forms and/or because two students can have the same experience, yet interpret it very differently. Put simply, it may be that the effects of the study abroad experience are sufficiently pervasive that they can be measured by instruments assessing very different constructs.

Therefore, if the goal is to assess whether improved intercultural development occurred as a result of students studying abroad, then this study's results offer support that both the GPI and the IDI can fulfill this role. However, we recommend that, given the lack of correlation between the different constructs of the two instruments, researchers should first determine if there are specific scales of intercultural development they wish to assess or if their goal is one of simply verifying that a particular study abroad program enhances intercultural development. 


\section{Directions for Future Research}

Study abroad programs are delivered in very different formats and often with substantially different objectives. It is likely that some program formats yield better results than others. The findings of this study are based on a semester-long program in an English-speaking country. A clear need exists to extend research to different types of programs and in different cultures so that most effective formats can be identified.

There are many instruments designed to measure aspects of intercultural development, but little has been reported as to how these alternative instruments compare. A key finding of this study is that two instruments purporting to measure a similar construct show remarkably little relationship to each other in terms of the correlations among their scales. A clear need exists to assess the validity of the various instruments and to develop a better picture of what each actually measures. Faculty members must understand the similarities and differences among the instruments so that they can select the tool that provides the best match for the objectives of their study abroad programs.

\section{References}

Anderson, P.H., Lawton, L., Rexeisen, R.J., and Hubbard, A.C., (2006) "Short-Term Study Abroad and Intercultural Sensitivity: A Pilot Study" International Journal of Intercultural Relations, 30 (4), 457- 469. Association to Advance Collegiate Schools of Business (2007) Eligibility Procedures and Accreditation Standards for Business Accreditation, pgs. 12 \& 74, http://www.aacsb.edu/accreditation/process/documents/AACSB_ STANDARDS_Revised_Jan07_Annotated.pdf

Braskamp, L.A., Braskamp, D. C. Merrill, K. C. \& M. Engberg (2010). Global Perspective Inventory. Retrieved September 1, 2010 , from https:// gpi.central.edu/supportDocs/manual.pdf

Braskamp, L. A., Braskamp, D. C., \& Merrill, K. C. (2009). Assessing progress in global learning and development of students with educational abroad experiences. Frontiers. 18, $101-118$.

Braskamp, L.A., Braskamp, D.C., \& Merrill, K.C. (2007). Global Perspectives Inventory. Retrieved August 31, 2009 from https://gpi.central.edu/ Braskamp, L.A., Braskamp, D.C., \& Merrill, K.C. Assessing progress in global learning and development of students with education abroad experiences. Frontiers: The Interdisciplinary Journal of Study Abroad. 101-118. Braskamp, L.A., Braskamp, D.C., \& Merrill, K.C. (2008). Global Perspectives Inventory (GPI): Its purpose, construction, potential uses, and psychometric characteristics. Retrieved January 12, 2010 from http://gpi.central.edu/supportDocs/manual.pdf. 
Chickering, A. \& L. A. Braskamp (Winter 2009). Developing a global perspective for personal and social responsibility. Peer Review. 11, $27-30$.

Corbitt, J.N. (1998). Global Awareness Profile. (Yarmouth, ME: Intercultural Press).

DeDee, L. \& Stewart, S. (2003). The effect of student participation in international study. Journal of Professional Nursing, 19(4), 237-42.

Engle, L. and Engle, J. (2004). Assessing Language Acquisition and Intercultural Sensitivity Development in Relation to Study Abroad Program Design. Frontiers: The Interdisciplinary Journal of Study Abroad, Volume X, Fall, 219-236.

Earnest, G. W. (2003). Study abroad: A powerful new approach for developing leadership capacities. Journal of Leadership Education, 2, 2-14.

Gillespe, J. (2002). Colleges Need Better Ways to Assess Study abroad Programs. The Chronicle of Higher Education. July 5, 2002.

Greenholtz, J. (2000). Assessing cross-cultural competence in transnational education: The Intercultural Development Inventory. Higher Education in Europe, 25(3), 411-416.

Hammer, M.R. and Bennett, M.J. (2002). The Intercultural Development Inventory (IDI) Manual. Portland, OR: Intercultural Communication Institute.

Hammer, M. R., Bennett, M. J., \& Wiseman, R. (2003). Measuring intercultural sensitivity: The intercultural development inventory. International Journal of Intercultural Relations, 27, 421-443.

Higher Learning Commission (2007), Overview of Accreditation,

Standards, 4c, p. 6, http://www.ncahlc.org/index.php?option=com_ docman\&task=cat_view\&gid=33\&Itemid $=236$

Institute of International Education. (2006). Open Doors 2006: Report on International Educational Exchange. New York, NY: IIE. http:// opendoors.iienetwork.org/file_depot/0-10000000/0-10000/3390/ folder/50084/Open+Doors+2006_FastFacts_FINAL.pdf

Kelly, G. (1963). A Theory of Personality. New York: Norton.

Landis D. and Bhagat, R.S. (1996). Handbook of Intercultural Training ( $2^{\text {nd }}$ Ed.) Thousand Oaks, CA. Sage.

Lincoln Commission's (2005). Report on Global Competence and National

Needs: One Million Students Studying Abroad. http://www.nafsa.org/_/ Document/_lincoln_commission_report.pdf

Medina-López-Portillo, A. (2004). Intercultural Learning Assessment: The Link between Program Duration and the Development of Intercultural Sensitivity. Frontiers: The Interdisciplinary Journal of Study Abroad, 


\section{Volume X, Fall, 179-199.}

Paige, R.M., Jacobs-Cassuto, M., Yershova, Y. and DeJaeghere (2003)

Assessing Intercultural Sensitivity: An Empirical Analysis of the

Hammer and Bennett Intercultural Development Inventory.

International Journal of Intercultural Relations, 27 (4), 467-486.

Paige, R. M., Cohen, A. D. and Shively, R. L. (2004). Assessing the impact of a strategies-based curriculum on language and culture learning abroad, Frontiers: The Interdisciplinary Journal of Study Abroad, Volume X, Fall, 253-276.

Patterson, P. (2006) Effect of Study Abroad in Intercultural Sensitivity, Unpublished Doctoral Dissertation.

Rexeisen, R. Anderson, P. Lawton, L. and Hubbard, A. (Fall, 2008) Study Abroad and Intercultural Development: A Longitudinal Study. Frontiers: the Interdisciplinary Journal of Study Abroad. Vol. XVII: 1-20. Savicki,V., Downing-Burnettea, R., Hellerb, L., Binderb, F. \& Suntingerb, W. (2004). Contrasts, changes, and correlates in actual and potential intercultural adjustment. International Journal of Intercultural Relations, 28, 311-329.

Shealy, C.M. (2004) A Model and Method for "Making" a CombinedIntegrated Psychologist: Equilintegration (EI) Theory and Beliefs, Events, and Values Inventory (BEVI). Journal of Clinical Psychology, Vol 60 (10), 1065-1090.

Sobania, N. \& L. A. Braskamp. (Winter 2009). Study abroad or study away: It's not merely semantics. Peer Review. 11, 17-20.

Vande Berg, M. (2001). The assessment of learning outcomes in study abroad. International Educator, 10 (2) 31.

Vande Berg, M., Connor-Linton, J., and Paige, R.M. (2009) The Georgetown Consortium Project: Interventions for Students Learning Abroad. Frontiers: the Interdisciplinary Journal of Study Abroad. Vol. XVIII: $1-75$. 


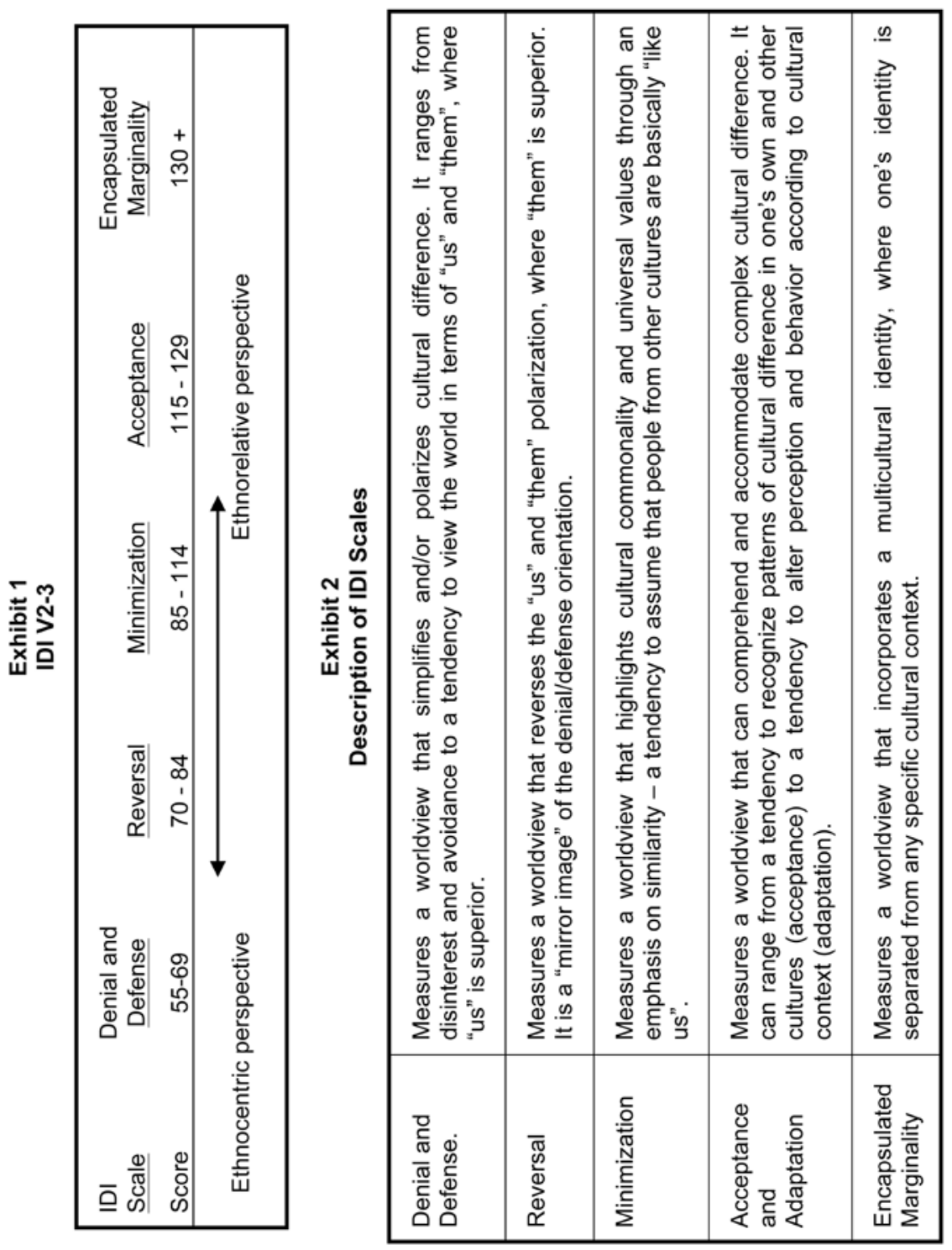




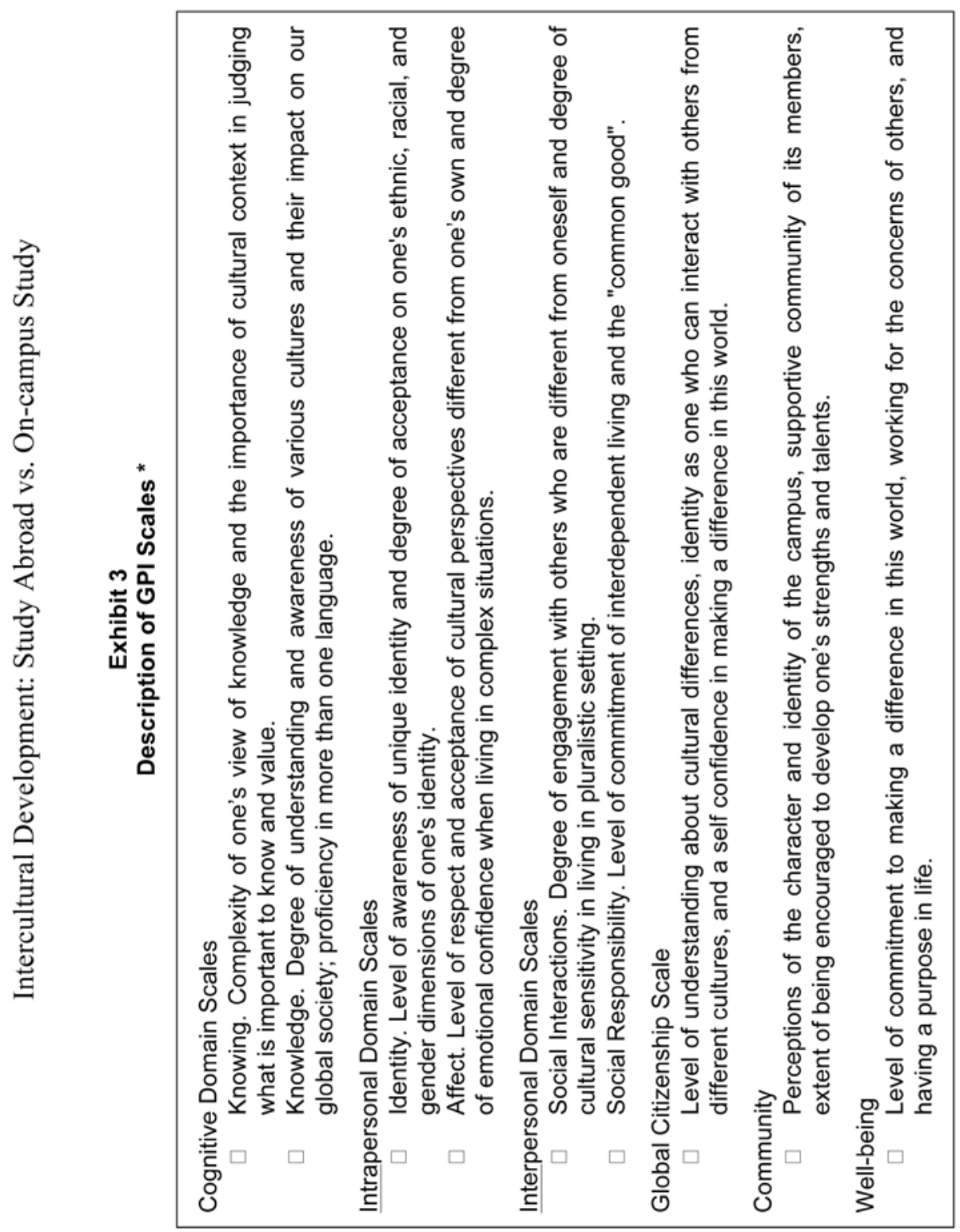




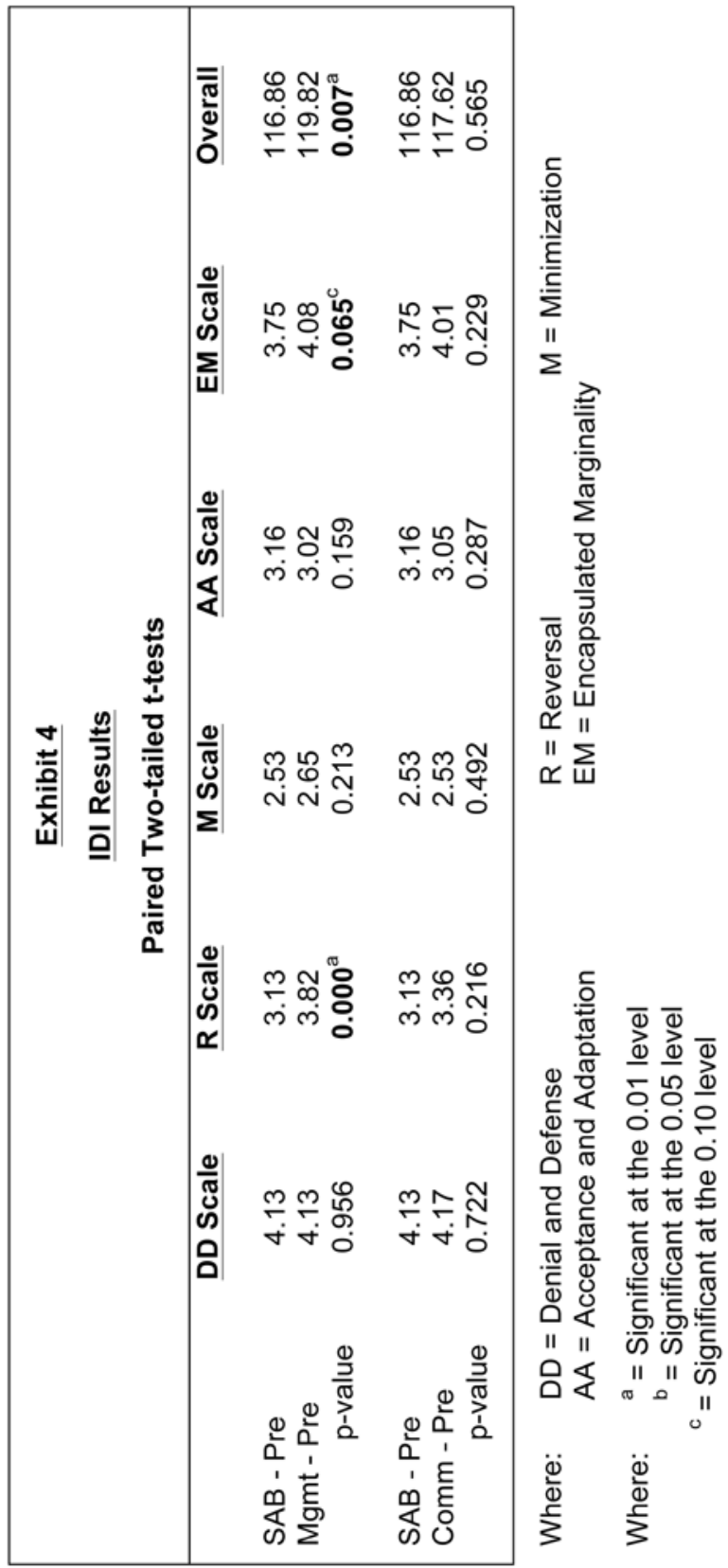




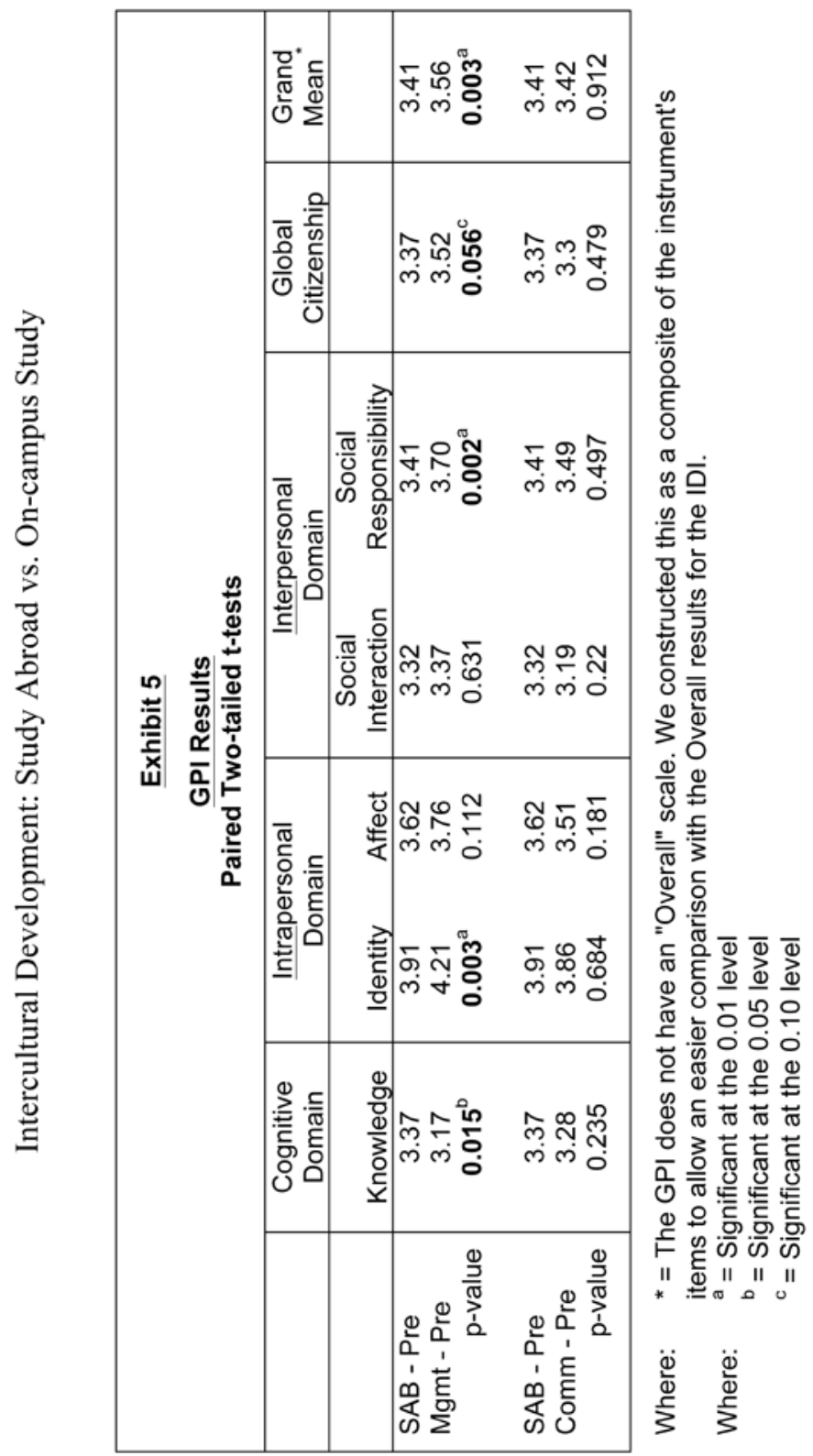




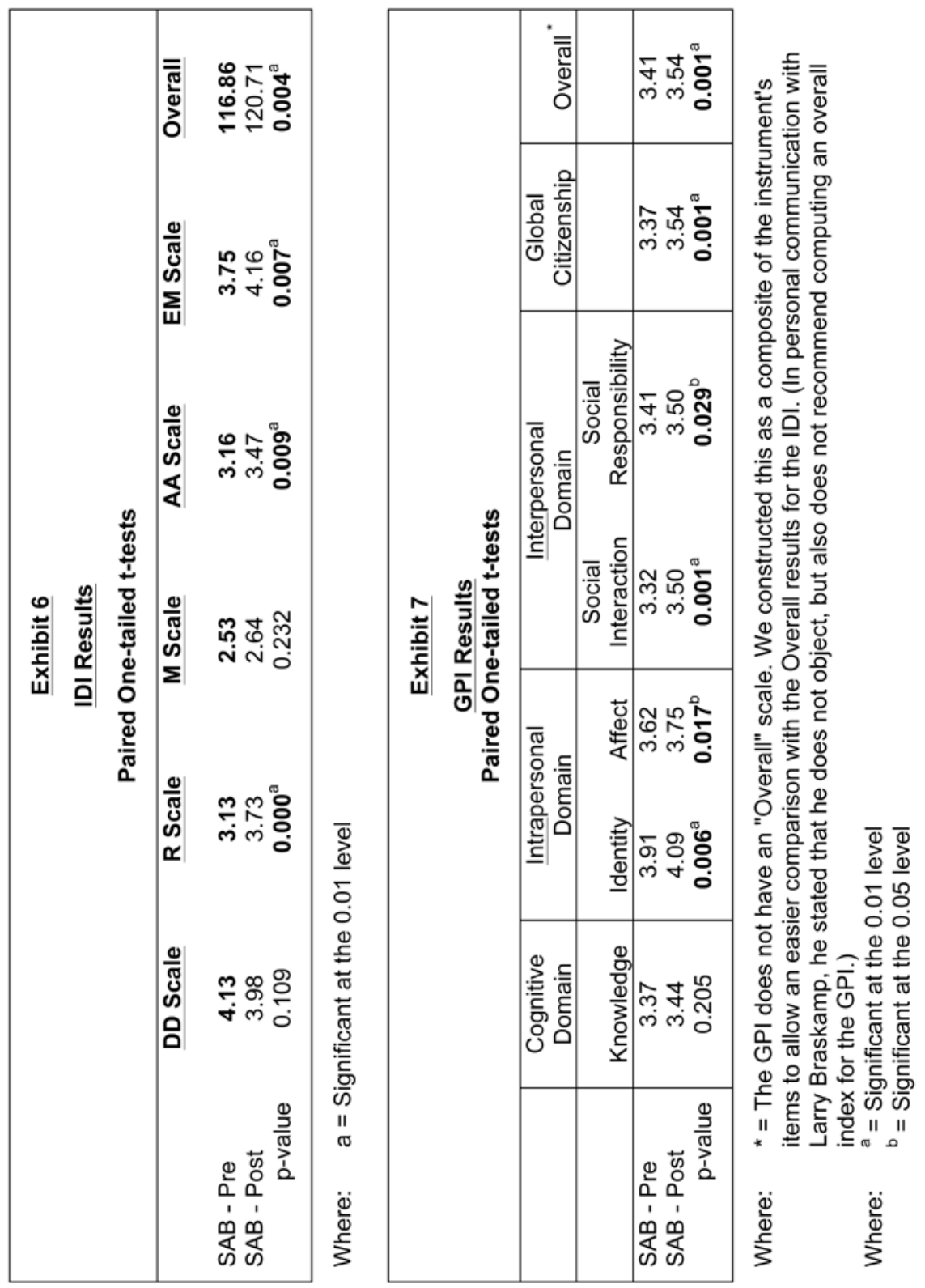




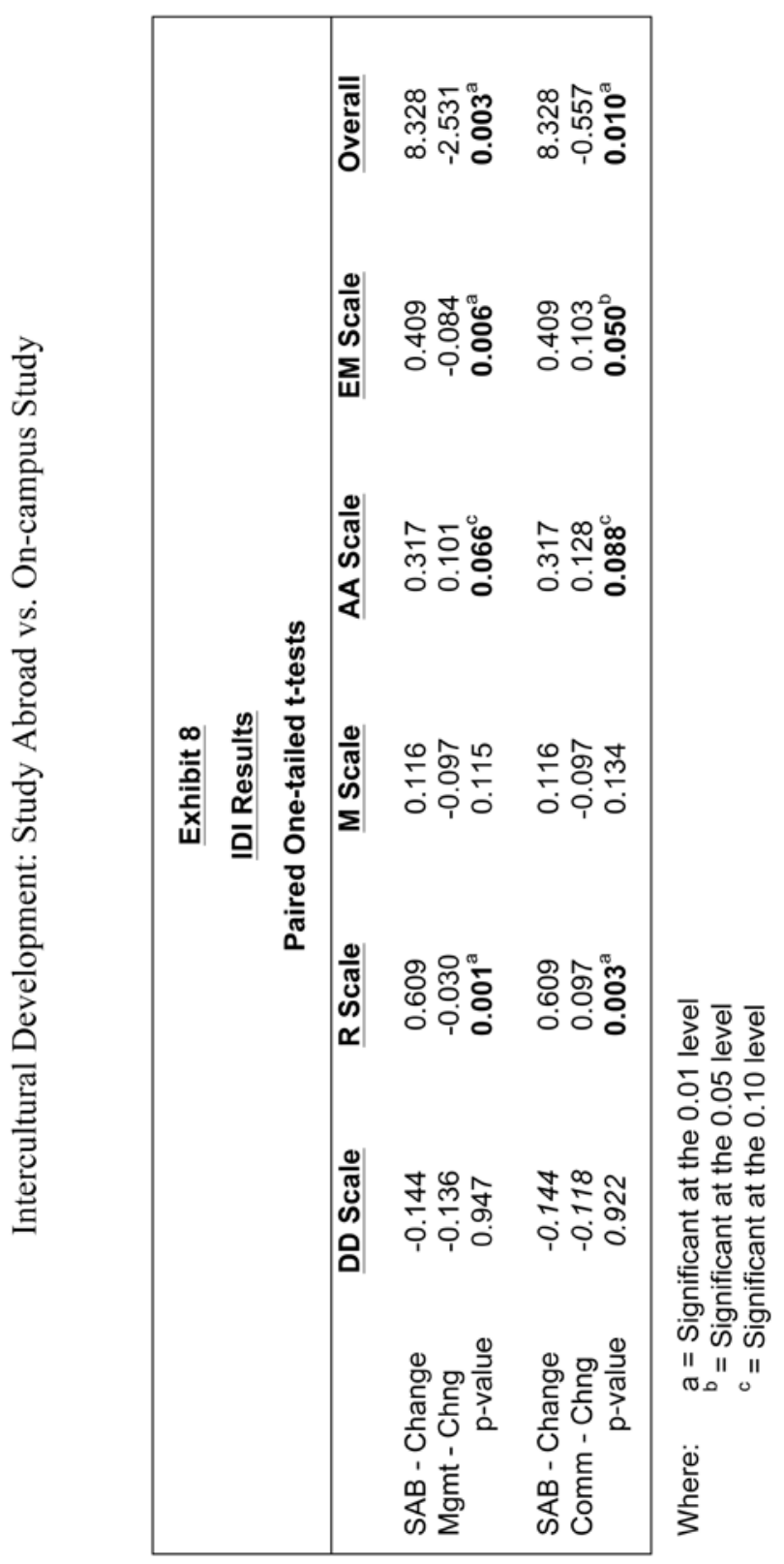




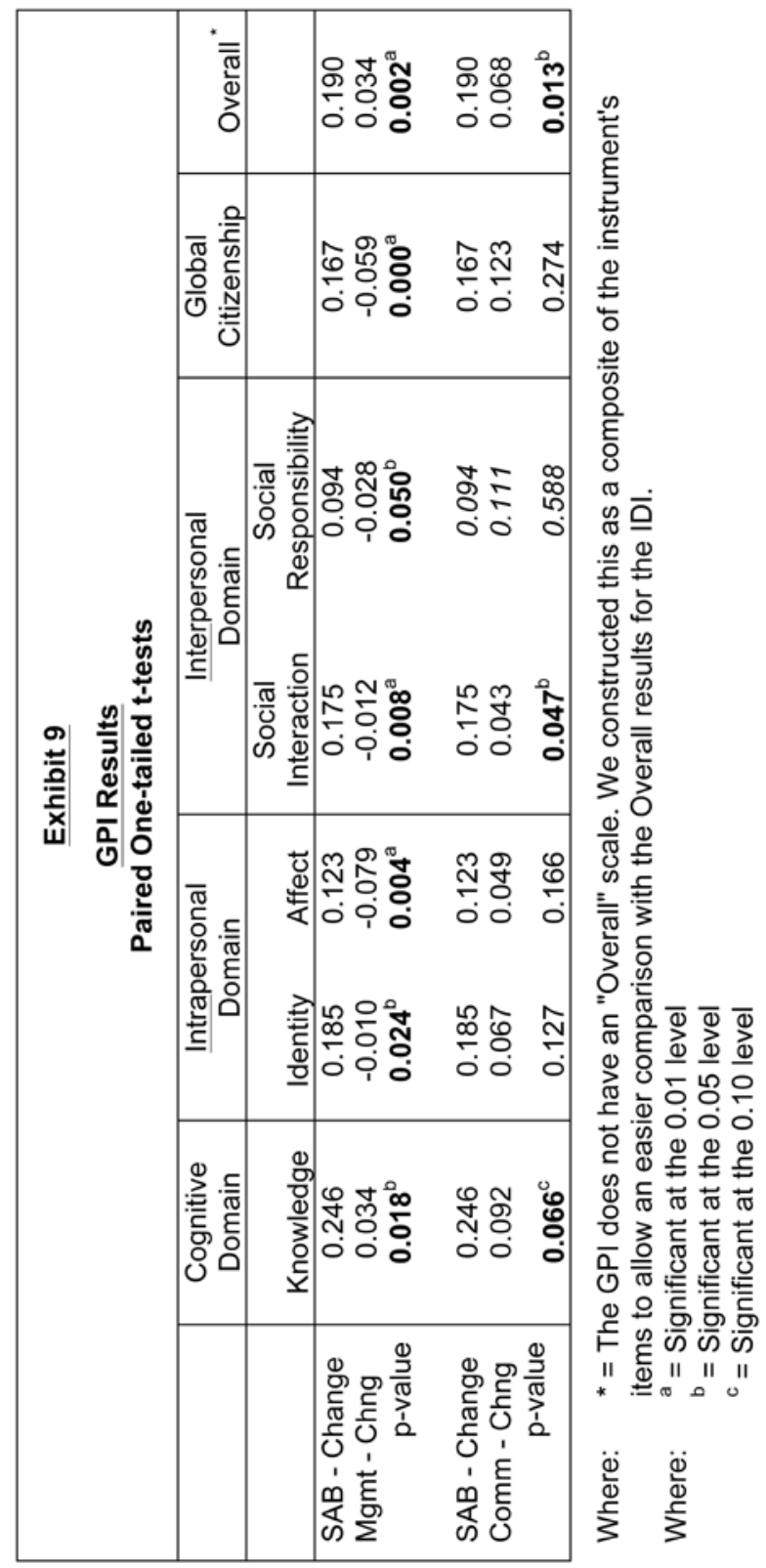


Philip H. Anderson and Leigh Lawton

\begin{tabular}{|c|c|c|c|c|c|c|}
\hline \multirow{7}{*}{ 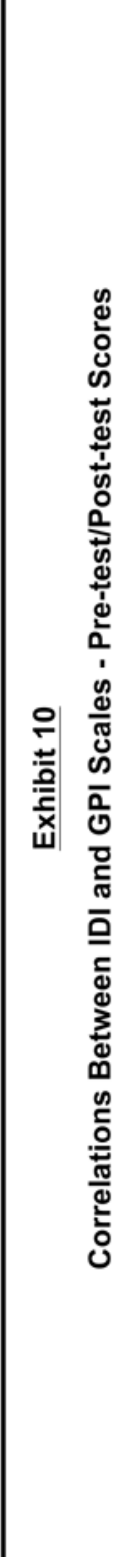 } & 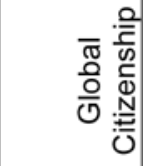 & 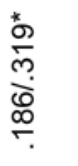 & $\begin{array}{l}\bar{\varphi} \\
\frac{1}{\infty} \\
\frac{\infty}{\tau}\end{array}$ & 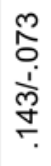 & $\begin{array}{l}\frac{0}{5} \\
\text { i } \\
\text { స̃ } \\
\stackrel{5}{\leftarrow}\end{array}$ & 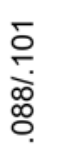 \\
\hline & 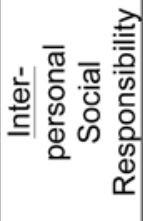 & 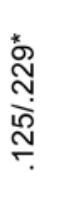 & 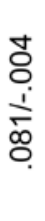 & 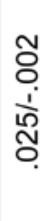 & $\begin{array}{l}\frac{n}{0} \\
\frac{1}{10} \\
0 \\
0\end{array}$ & 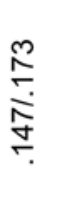 \\
\hline & 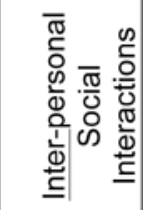 & 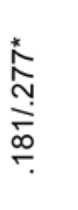 & 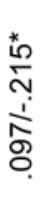 & 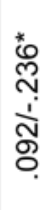 & 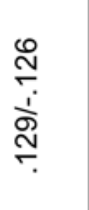 & 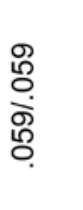 \\
\hline & 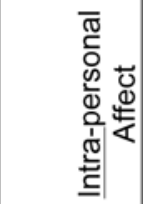 & $\begin{array}{l}\stackrel{*}{N} \\
\stackrel{\text { }}{*} \\
\stackrel{*}{*} \\
\stackrel{n}{n}\end{array}$ & 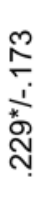 & 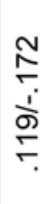 & 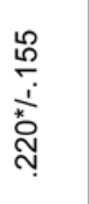 & $\frac{\text { 음 }}{\frac{5}{0}}$ \\
\hline & 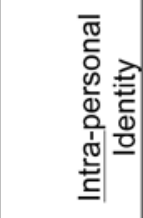 & 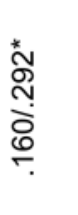 & 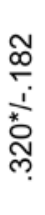 & 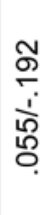 & 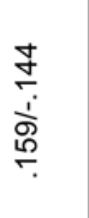 & 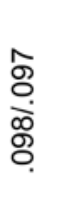 \\
\hline & 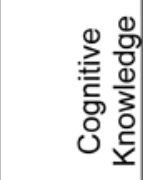 & 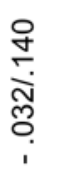 & 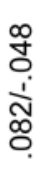 & $\begin{array}{l}\text { o } \\
\text { ○ } \\
\frac{1}{\infty 0} \\
8 \\
\\
i\end{array}$ & 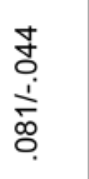 & 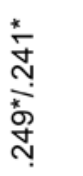 \\
\hline & & 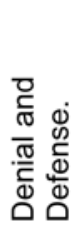 & 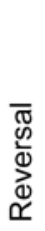 & 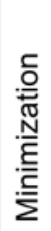 & 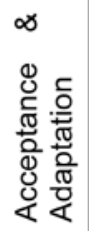 & 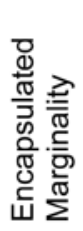 \\
\hline
\end{tabular}

